\title{
Evaluating The Influence Of Physical Education Programs Based On A Game Approach To The Actual Motor Capacity Of Elementary School Children
}

\author{
Dr. Doan Tien Trung ${ }^{1}$, Dr. Pham Thi Le Hang ${ }^{2}$ \\ ${ }^{1}$ Physical Education Deparment, Ho Chi Minh City University of Education, Ho Chi Minh City, VIETNAM \\ 2 \\ Physical Education Deparment, Ho Chi Minh City University of Education, Ho Chi Minh City, VIETNAM
}

DOI https://doi.org/10.15520/ijmhs.v9i10.2716

Reviewed By: Dr.

Daniel V.

Department: Medical

\section{Abstract}

This study is to test the effectiveness of the program on the development of the basic motor skills by taking into account the degree of movement in overtime activities of sampled participants and their gender. The study included 74 children (36 men and 38 women; average age: 9 years). According to these data, children were grouped into two moving levels (i.e., High and Low) and, for each group by sex, a t-sample test was performed to assess the level of actual motor capacity development before and after the project. Males who were brought into the lowlevel movement group had a significant improvement in the location and the coarse engine development negotiation score (which is most likely and likely to have a positive effect). A contradictory effect is estimated for women: only girls in high-level movements show significant and likely positive effects of treatment in their motor scores. These results highlight the effect of analyzing the physical education program, although the relative positive results on the selected participants are not enough to overcome the problems of child malnutrition that the document always emphasizes.

Keywords: Check for development of Gross engine; teaching methods; extracurricular activities; teaching-learning process.

\section{INTRODUCTION}

It is well known that the fundamental motor skills (FMS) is related with the physical activity and the sport practice. Particularly, the importance of motor development and its influence on the physical activity were regarded as the focus point of the research (Logan et al., 2015; Francesco et al., 2019). In this respect, some authors hypothesized that a greater commitment in physical activity is linked with a good level of FMS (Stodden et al., 2008) and that a child skilled in physical activities will be more active people as well (Clark, 2005). The importance of 
FMS is also supported by the large amount of studies that investigate several aspects related to the teaching-learning process, such as the usefulness of several and various assessment methods (Sgrò et al., 2016).

Several of reasons have been pointed out as the cause of this problem: the time of playing video games, low availability of physical activity and sport fields, and the low level of physical and sporting education in schooltime. In contrast, the school is widely recognized as an important environment to support skills, knowledge and behavior towards physical activity and sports throughout life. In this regard, physical education (PE) lessons require high quality teaching methods, more lessons per week and a strong relationship with extra-school physical activity and sports clubs for providing additional opportunities.

In Vietnam, as in other Asian countries, primary education lessons on the primary level are not given to well-trained, irregular teachers and the effects of those lessons on delivery. The development of the full FMS level is significantly limited. Recently, to overcome the above problems, a physical education project has been supported and implemented by the Vietnam National Ministry of Education, University and Research and the Olympics. Therefore, by considering similar initiatives that can be implemented in the following years as well as in other Asian countries, the purpose of this study is to examine the effectiveness of the above project for with the actual motor capacity of students who participate in related physical education and sports lessons by taking into account the level of movement in overtime activities of sampled participants and the gender of they.

\section{MATERIAL AND METHODS}

The participants of this study were sampled from a primary school of a city located in the South of Vietnam.

The participants were 74: male: 36; female:38; mean age:9 years old; mean height: $1.34 \mathrm{~m}$; mean weight: $35.02 \mathrm{Kg}$. The participants were involved in a physical education curriculum that will be described in the following sections of this manuscript. The project is managed for 5 months and the levels of actual motor competences were verified pre- and post-project' teaching activities. Assessment procedures were performed at the school gym, where almost four skilled operators met the participants. Overall, the evaluation time is six days. For each day, to ensure valid and reliable assessment procedures, participants are divided into the smallest group (i.e., five children per group). Anthropometric measures are performed from the same operator for all participants using a wall mounted meter for height and electronic weighing scales; These measures were used to estimate Body Mass Index (BMI) of $\mathrm{Kg} / \mathrm{m}^{2}$ of each child.

\section{Actual motor competence assessment}

The level of crude engine development was measured by the Test of Gross-Motor Development (TGMD) (Ulrich, 1985). TGMD is composed by 12-item test divided into loco motor (run, gallop, hop, leap, standing horizontal jump, slide) and control objects (strike, stationary ball bounce, catch, kick, overhand throw) sub tests. Three to four skill criteria are specific to each item and the operator must determine whether a child is proficient or not. For each item, the participants performed three tests; Before the evaluation started, participants participated in a low intensity startup program for ten minutes. For each test, the raw score allowed testing 
locomotives ranged from 0 to 26 , while the raw score for controlling subjects controlled subjects ranged from 0 to 19 . The raw score of each participant is converted into a benchmark for each test, individually, according to the age of each child. Next, the standard score was used to estimate Gross Motor Development Quotient (GMDQ). GMDQ has been used to explain the child's actual motor capacity level according to the normative data provided in GMDQ (i.e., very low, low, under the mean, mean, over the mean, high, very high). In the current study, four operators were involved in assessing the development of crude engines by means of GMDQ. The executives have followed the performance of each item in the gym, and they have recorded the performance videos of each child. After that, the evaluation of each test was performed by each operator, separately, with Longomtach software (LongoMatch, Ver. 0.20.8, http://longomatch.org) taking up some processes (e.g., : slow motion, moving videos forward and behind the frame on each frame) useful to provide a valid and reliable assessment of participants' performance. The reliability between the measurements ranges from 0.87 allowing the test of the machine to 0.91 to allow for control of the object.

\section{Children's Recreational Activities Study Survey (CRASS)}

CRASS is a questionnaire used to investigate the children's extra-school daily routine in terms of physical and sport activities (i.e., 30 items like dance, tennis, soccer, to ride a bike, etc.) and recreational activities (i.e., 14 items like playing a musical instrument) (Telford et al., 2005). For each activity, it is necessary to report the frequency (how many times from Monday to Friday and how many times on weekend) and the total time spent by the child in these activities (minutes or total hours from Monday to Friday and from Saturday to Sunday). The version of CRASS used in this study was the proxy-report, since the parents filled the questionnaire according to the activities performed by their child during the aforementioned periods. According to cultural and geographical location of the participants engaged in this study, some physical activities were selected and grouped together into three categories with homogeneous characteristics: sport, physical activity, and leisure. This procedure agreed with the one used in previous studies (Howley, 2001). Moreover, for overcoming statistical problem related to a lot of structural zeroes obtained for many activities, the next step was to commute the time spent for each of the aforementioned three categories in dichotomous variables: a) from 0 to 120 minutes; b) more than 120 minutes. Finally, two levels of motion were defined according to the obtained time: a) Low Level of Motion (LLoM): participants were included in this category if their physical activity and sport time were from 0 to 120 minutes; b) High Level of Motion (HLoM): participants were included in this category if their physical activity and sport time were more than 120 minutes;

It requires the involvement of a specialized expert in physical education, called "school sport tutor", who is appropriate trained for the project and works alongside the teacher for one hour a week, collaborating in planning and implementing motor activities. As regard to the teachinglearning activities considered in this study, the tutor developed a teaching plan following the Vietnamese National Guidelines for the development of the curriculum of physical education in primary school and he has carried out PE lessons based on games activities. 
These lessons included team and individual games and they differ from the sport-based training approach because the rules of the games are not codified, they do not cause early selection neither specialization, and small-sided games and circuit were used as prominent teaching approach. Circuits have been developed using available tools, such as cones, mats, over, balls, obstacles, and rope,... The participants involved in this project were year 9 to 10 students and they followed the treatment for twenty weeks during the last school's year.

\section{Data analysis}

First, data related to motor competence were checked for verifying whether they were normally distributed or accounted for some univariate outliers. Then, according to the level of motion and gender, student's t tests for paired samples were conducted for verifying if exist a significant effect of the SdC project on the level of actual motor competence. If significant effect was found, the size of that effect was established by means of the non-clinical magnitude-based inference method (Hopkins et al., 2009).

The interpretation of the effects in a negative, trivial, or positive practical sense on the dependent variables (i.e., Locomotor score, Object control score, and GMDQ) was based on the following thresholds: $<0.5 \%$ most unlikely; $0.5-5 \%$ very unlikely; $5-25 \%$ unlikely; $25-75 \%$ possibly;75-95\% likely; 95-99.5\% very likely; and $>99.5 \%$ most likely (Batterham \& Hopkins, 2006). For each significant effect, we reported the $\mathrm{t}$-value $(\mathrm{t})$, the degrees of freedom (df), p-value, 90\% confidence limits (CI90\%), and the practical inference true effect, as suggested by Hopkins and colleagues (2009). The analyses were conducted using SPSS 20.0 and the alpha level was set to 0.05 in all tests.

\section{RESULTS}

Data analysis results show that 12 subjects are not different, so their data has been removed from further analysis. Because no other violations were verified, parametric analyzes were performed.

Table 1: Describe children's anthropometric characteristics according to their movement level.

\begin{tabular}{|l|l|l|l|l|}
\hline \multirow{2}{*}{} & \multicolumn{2}{|c|}{$\begin{array}{c}\text { Low Level of } \\
\text { Motion } \\
(\mathrm{n}=30)\end{array}$} & \multicolumn{2}{|c|}{$\begin{array}{c}\text { High Level of } \\
\text { Motion } \\
(\mathrm{n}=32)\end{array}$} \\
\cline { 2 - 5 } & $\mathrm{M}$ & SD & M & SD \\
\hline Age (year) & 9.40 & 0.63 & 9.28 & 0.68 \\
\hline Height (m) & 1.31 & 0.72 & 1.35 & 0.63 \\
\hline $\begin{array}{l}\text { Weight } \\
(\mathrm{kg})\end{array}$ & 32.12 & 10.15 & 34.24 & 9.32 \\
\hline $\begin{array}{l}\text { BMI } \\
\left(\mathrm{kg} / \mathrm{m}^{2}\right)\end{array}$ & 1.78 & 0.42 & 1.84 & 0.31 \\
\hline
\end{tabular}

The further results are presented by following the analysis according to the participants' level of motion and, for each level, to participants' gender.

\section{Participants with low level of motion}

By considering the overall sample classified in the low level of motion, no significant differences were noted between the score pre- and postproject for the three parameters considered as proxy of the actual level of motor competence. If the gender was used as factor, significant effect of the lessons on motor competence was identified only for the male. In detail, significant differences were noted for: -) locomotor score ( $\mathrm{t}=$ $3.45, \mathrm{df}=21, \mathrm{p}=0.001,90 \%$ confidence limits 2.0 to 5.2, most likely): the score related to these abilities was higher in the post- than in prelessons assessment; -) GMDQ ( $\mathrm{t}=1.98, \mathrm{df}=22$, $\mathrm{p}=0.05,90 \%$ confidence limits 0.4 to 3.6 , likely: the score used for quantifying the overall level of gross-motor skills development was higher in the post- than in pre-lessons assessment; The images 
in Figure n. 1 show the influence of the treatment according to the GMDQ's aforementioned levels.

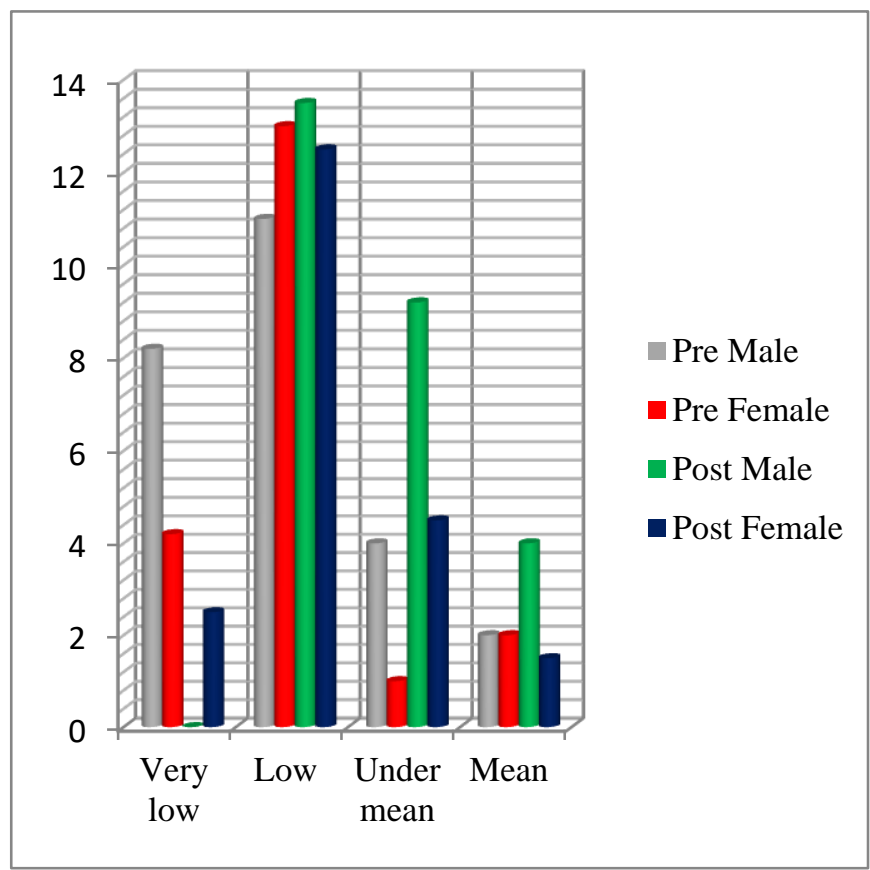

Figure 1 - GM QD levels in low level of motion participants (LLoM) pre- and post-lessons Participants with high level of motion

By considering the overall sample classified in the high level of motion, significant differences were noted between the score pre- and postlessons for the following parameters: -) locomotor score $(\mathrm{t}=3.32, \mathrm{df}=23, \mathrm{p}=0.001,90 \%$ confidence limits 2.0 to 5.4 , most likely): the score related to these abilities was higher in the post- than in pre-lessons assessment; -) GMDQ $(\mathrm{t}=2.09, \mathrm{df}=23, \mathrm{p}=0.03,90 \%$ confidence limits 0.6 to 4.2, very likely: the score used for quantifying the overall level of gross-motor skills development was higher in the post- than in prelessons assessment; If the gender was used as factor, significant effect of the teaching-learning project on motor competence was identified only for the female. In detail, significant differences were noted for: -$)$ locomotor score $(\mathrm{t}=3.10$, $\mathrm{df}=$ $13, \mathrm{p}=0.001$, $90 \%$ confidence limits 1.3 to 4.1 , very likely): the score related to these abilities was higher in the post- than in pre-lessons assessment;

The images in Figure n. 2 show the influence of the treatment according to the GMDQ's aforementioned levels.

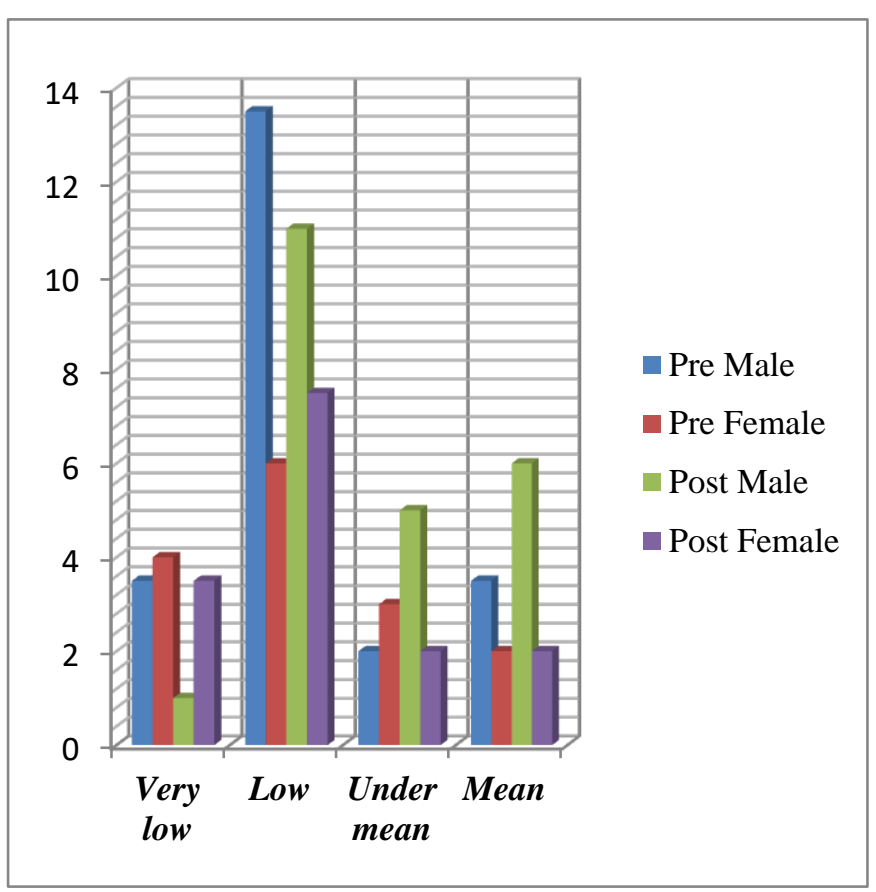

Figure 2 - GMQD levels in high level of motion participants (HLOM) pre- and postlessons

\section{DISCUSSION}

The purpose of this study was to evaluate whether the project "Sport di Classe" had an influence on the FMS development of Vietnamese children according to their level of motion and gender. Overall, the current results highlighted statistically significant positive differences in locomotion scores and GMDQ for the males. Girls showed a significant improvement only in locomotion scores. No significant differences were found in object control scores. These results are in partial agreement with previous similar 
studies which have shown that male are more skilled than females. (Valentini et al., 2016; Sgrò et al. 2017). Other studies that have addressed the effect of physical activity interventions on fundamental movement skills underlined an improvement of such skills (Brusseau, et al., 2016). Bryant and colleagues (2016) found that one day per week of physical education protocol performed by a class of Year 4 and Year 5 (experimental group) increased significantly mastery of fundamental movement skills, pedometer step and physical self-perception in comparison with a peer-age class enrolled in a game-based physical education process (control group). As regard to the evidences of the CRASS questionnaire and their relationship with the scores obtained in the GMDQ, the current result show that the males, who have been included in the Low Level of Motion group (LLoM) had an improvement more significant than the ones of the High Level of Motion (HLoM) group both in locomotion and in GMDQ scores. A contrary effect it was estimated for the females: only the girls classified in the HLoM were affected by a significant and very likely positive effect of the treatment in their locomotion scores. In line with these results, the influence of the $\mathrm{SdC}$ project seems to be different according to gender, level of motion, and skills typologies and this evidence need to be considered for developing effective curriculum and teaching strategy.

\section{CONCLUSION}

Results are similar to previous studies (Hardy et al., 2012). Developing FMS should be an important strategy in early childhood interventions aimed at promoting long-term physical activity, especially in elementary schools. Indeed, the appropriate development of FMS can affect the degree to which capabilities are implemented and this may affect the level of potential activity achieved in physical education activities (Fairclough \& Stratton, 2005).

However, the overall level of gross motor development remains under the mean provided by Ulrich's normative data both in the assessment performed before and after the PE lessons, as shown in the figures 1 and 2 .

For this reason, the expectation is that children are more skilled than less experienced children. In fact, in the analysis of Hardy and colleagues, low scores in object control and mobility are related to inactive subjects. In a review written by Logan and colleagues (2015), studies have found a positive relationship between FMS and physical activity, except that the research was developed by Erwin and Castelli (2008).

So, "in accordance with the trends identified by Dordel (2000), as the decades passed, there is a lowering of the critical age where the children motor performances taking negatives features in respect with the past standard values" (Filippone et al.,2007). It can be assumed that this becomes worse, in the context of the relationship between physical activity and FMS, due to the dissatisfaction of the physical activity guidelines of children and adolescents.

However, although there is growing evidence of the importance of FMS and its link to the physical and psychosocial development of children (Logan et al., 2012), the literature emphasized these capabilities in children and adolescents. (O'Brien et al., 2016). The most worrisome feature is the warning that, over the generations, the worsening trend of engine power indicators is generally a change in age prediction.

Current results are consistent with the aforementioned analysis, and they confirm that an 
on-site inspection protocol of physical activity is not sufficient to improve the level of FMS development to an appropriate score. Moreover, it has been verified that the development of FMS needs to be supported by the real physical education process based on student mobility and it needs to take into account the students and the gender of the sport, and the level of movement. However, the current results are affected by a number of limitations, such as low sample size and the lack of any useful factors to verify project effectiveness for cognitive learning areas, and social relationships. These factors need to be strongly considered planning for new studies with the aim of closely related to the studies mentioned in this study.

The main points of current and useful research for practitioners are:

i. Low level of FMS development is still an important issue to face with all stakeholders in education plan;

ii. The effectiveness of physical education lessons is analyzed, although the relative positive results for the selected participants are not enough to overcome the aforementioned problems and to establish a heterogeneous effect to support a healthy lifestyle throughout life;

iii. Physical education goals can be achieved if they are supported, in elementary schools, with an effective curriculum based on wellknown teaching strategies such as gamefocused and tactical methods.

\section{REFERENCES}

1. Batterham, A. M., \& Hopkins, W. G. (2006). Making meaningful inferences about magnitudes. International journal of sports physiology and performance, 1(1), 50-57.

2. Brusseau, T. A., Hannon, J. C., \& Burns, R. D. (2016). Effect of a Comprehensive School Physical Activity Program on physical activity and health-related fitness in children from low-income families. Journal of Physical Activity and Health, 13, 888-894.

3. Bryant, E. S., Duncan, M. J., Birch, S. L., \& James, R. S. (2016). Can fundamental movement skill mastery be increased via a six week physical activity intervention to have positive effects on physical activity and physical self-perception? Sports, 4(1), 10.

4. Clark, J.E.(2005). From the beginning: a developmental perspective on movement and mobility.Quest, 57(1), 37

5. Dordel, S. (2000). Kindheit heute: veränderte Lebensbedingungen= reduzierte motorische Leistungsfähigkeit. Sportunterricht, 49(11), 341-349.

6. Erwin, H. E., \& Castelli, D. M. (2008). National physical education standards: A summary of student performance and its correlates. Research Quarterly for Exercise and Sport, 79(4), 495-505.

7. Fairclough, S., \& Stratton, G. (2005). Physical activity levels in middle and high school physical education: a review. Pediatric exercise science, 17(3), 217-236.

8. Francesco S, Antonella Q, Fabiana P \& Mario L, (2019). Assessing the impact of a physical education project based on games approach on the actual motor competence of primary school children. Journal of Physical Education and Sport, 19 (3), pp $781-786$ 
9. Filippone, B., Vantini, C., Bellucci, M., Faigenbaum, A. D., Casella, R., \& Pesce, C. (2007). Trend secolari di involuzione delle capacità motorie in età scolare. SDS, 72,31 .

10. Hardy, L. L., Reinten-Reynolds, T., Espinel, P., Zask, A., \& Okely, A. D. (2012). Prevalence and correlates of low fundamental movement skill competency in children. Pediatrics, 130(2).

11. Hopkins, W., Marshall, S., Batterham, A., \& Hanin, J. (2009). Progressive statistics for studies in sports medicine and exercise science. Medicine \& Science in Sports \& Exercise, 41(1), 3-12.

12. Howley, E. T. (2001). Type of activity: resistance, aerobic and leisure versus occupational physical activity. Medicine \& Science in Sports \& Exercise, 33(6), S364-S369

13. Logan, S. W., Robinson, L. E., Wilson, A. E., \& Lucas, W. A. (2012). Getting the fundamentals of movement: a metaZanalysis of the effectiveness of motor skill interventions in children. Child: care, health and development, 38(3), 305-315.

14. Logan, S. W., Kipling Webster, E., Getchell, N., Pfeiffer, K. A., \& Robinson, L. E. (2015). Relationship between fundamental motor skill competence and physical activity during childhood and adolescence: A systematic review. Kinesiology Review, 4(4), 416-426.

15. O'Brien, W., Belton, S., \& Issartel, J. (2016). Fundamental movement skill proficiency amongst adolescent youth. Physical Education and Sport Pedagogy, 21(6), 557-571.
16. Sgrò, F., Quinto, A., Pignato, S., \& Lipoma, M. (2016). Comparison of product- and process-oriented model accuracy for assessing countermovement vertical jump motor proficiency in preadolescents. Journal of Physical Education and Sport. 16(3), 921-926.

17. Sgrò, F., Quinto, A., Messana, L., Pignato, S., \& Lipoma, M. (2017). Assessment of gross motor developmental level in Italian primary school children. Journal of Physical Education and Sport. 17(3), 1954-1959.

18. Sgrò, F., Mango, P., Pignato, S., Schembri, R., Licari, D., Lipoma, M. (2017). Assessing Standing Long Jump Developmental Levels Using an Inertial Measurement Unit. Perceptual and Motor Skills. Perceptual and Motor Skills, 124(1), 21-38.

19. Sgrò, F., Bracco, S., Pignato, S., \& Lipoma, M. (2018). Small-Sided Games and Technical Skills in Soccer Training: Systematic Review and Implications for Sport and Physical Education Practitioners. Journal of Sports Science. 6(1), 9-19.

20. Stodden, D. F., Goodway, J. D., Langendorfer, S. J., Roberton, M. A., Rudisill, M. E., Garcia, C., \& Garcia, L.

21. Telford, A., Salmon, J., Timperio, A., \& Crawford, D. (2005). Quantifying and Characterizing Physical Activity AMong 5-to 6-and 10-to 12-Year-Old Children: The Children's Leisure Activities Study (CLASS). Pediatric Exercise Science, 17(3), 266-280.

22. Ulrich, D. A. (1985). Test of gross motor development. Austin, TX: Pro-ED. Inc. US Department of Health and Human 
Services. 2008 Physical Activity Guidelines for Americans. Washington (DC): ODPHP Publication No. U0036; 2008 [cited $2011 \mathrm{Jul}$ 4]. Available from:

23. Valentini N.C., Logan S., Spessato B., Santayana de Souza M., Keila G. Pereira, Rudisill M., (2016) Fundamental Motor Skills Across Childhood: Age, Sex, and Competence Outcomes of Brazilian Children, Journal of Motor Learning and Development, 4(1), 16 -36.

\section{AUTHOR BIOGRAPHY}

Dr.Doan Tien Trung, Physical Education Deparment, Ho Chi Minh City University of Education, Ho Chi Minh City, VIETNAM

Dr.Pham Thi Le Hang, Physical Education Deparment, Ho Chi Minh City University of Education, Ho Chi Minh City, VIETNAM 